\title{
Los deberes fundamentales y la Constitución brasileña*
}

\author{
Julio Pinheiro Faro Homem de Siqueira**
}

\begin{abstract}
RESUMEN
Este artículo presenta algunos aspectos de la tan olvidada temática sobre los deberes fundamentales con especial referencia a la Constitución brasileña de 1988. En esto aspecto, el artículo aborda la escasez de estudios acerca de este asunto, ofreciendo algunas ideas sobre la clasificación de los deberes fundamentales, su régimen jurídico-constitucional y sobre el concepto de los mismos. Así, utiliza algunos de los principales trabajos sobre él existentes en la literatura brasileña.
\end{abstract}

Deberes fundamentales - Constitución brasileña - clasificación de deberes fundamentales

\section{Fundamental duties and the Brazilian Constitution}

\begin{abstract}
This article intends to present some of the aspects on the forgotten fundamental duties thematic with a special emphasis on the Brazilian Constitution of 1988. Thus, this work takes into account the lack of studies on this matter, bringing some ideas on the fundamental duties classification, legal regimen and concept. For this, it uses some of the main Brazilian works that exists on this matter.
\end{abstract}

\author{
Fundamental duties - Brazilian Constitution - classification of \\ fundamental duties
}

* Agradezco al amigo y profesor J. Alberto del Real Alcalá por las sugerencias.

** Abogado, Secretario General de la Academia Brasileña de Derechos Humanos (ABDH); Rua Joaquim Lirio, 197/301, Praia do Canto, Vitoria-ES/Brasil, 29055-460. julio.pfhs@gmail.com

Artículo recibido el 30 de marzo de 2011 y aceptado para su publicación por el Comité Editorial el 27 de mayo de 2011. 


\section{INTRODUCCIÓN}

$\mathrm{L}$ a Constitución de la República brasileña de 1988 o CR recoge expresamente en su texto, en el capítulo primero del título primero, la existencia de deberes fundamentales. En otros lugares del propio texto constitucional es posible encontrar referencias directas a tales deberes, y, aún, es posible extraer deberes implícitos del texto. Sin embargo, la doctrina y la jurisprudencia se han centrado habitualmente en abordar y desarrollar los derechos, lo que ha provocado el olvido de los deberes ${ }^{1}$. Razón por la que oportunamente algunas voces se han levantado para afirmar que el tema de los deberes es una de las cuestiones en las que la doctrina constitucional contemporánea más se olvidó de cultivar $^{2}$. Esta breve contribución tiene el propósito de proporcionar algunas observaciones sobre el asunto, especialmente en relación al derecho brasileño, en el que escasean los estudios acerca de este tema ${ }^{3}$. Así, ese breve artículo trae algunos delineamientos que la dogmática jurídica deberá enfrentar al tratar sobre la cuestión de los deberes fundamentales.

\section{Consideraciones generales}

Los deberes fundamentales deben ser concebidos en el mismo nivel que los derechos fundamentales ${ }^{4}$, pues no es posible hoy considerar al individuo como portador únicamente de derechos, debiéndosele observar también como sujeto de deberes -en relación a sí mismo, a la sociedad y a las generaciones futuras.

La idea de los seres humanos como sujetos de derechos y de deberes tiene mucho en común con el mundo antiguo, pero se perdió con el tiempo en la historia de la sociedad occidental, de manera que la noción del ser humano en cuanto detentor de un compromiso con su comunidad o sociedad perdió valor, sobre todo a partir de la necesidad de proteger a los individuos de las injerencias estatales. Ante este cuadro, hablar de derechos sólo individuales fue lo común especialmente a partir del constitucionalismo de la era de las revoluciones (siglo XVIII). Hoy en día este modelo -ya vetusto- necesita ser sustituido en razón de que las personas poseen tanto derechos como deberes, implicando los unos la existencia de los otros 5 .

${ }^{1}$ Canotilho, J.J.G., "Das constituições dos direitos à crítica dos direitos", en Direito Público, Brasília, n. 7, 2005, p. 80 .

${ }^{2}$ Nabais, J.C., O dever fundamental de pagar impostos: contributo para a compreensão constitucional do estado fiscal contemporâneo, Coimbra, Almedina, 2004, p. 15.

${ }^{3}$ Sarlet, I.W., A eficácia dos direitos fundamentais: uma teoria geral dos direitos fundamentais na perspectiva constitucional, 10. ed., Porto Alegre, Livraria do Advogado, 2009, p. 226.

${ }^{4}$ Nabais, José Casalta, O dever fundamental de pagar impostos: contributo para a compreensão constitucional do estado fiscal contemporâneo, Coimbra, Almedina, 2004, p. 64; Peces-Barba Martínez, G., "Los deberes fundamentales”, Doxa, Alicante, n. 4, 1987, p. 330.

${ }^{5}$ Lopes, A.M.D., "A participação política das minorias no Estado democrático de direito brasileiro", en Lima, M.M.; Albuquerque, P.A.M. (org.), Democracia, direito e política: estudos internacionais em homenagem a Friedrich Müller, Florianópolis, Conceito, 2006, p. 84-87. 
Según Gregorio Peces-Barba ${ }^{6}$, el concepto de deber tiene, históricamente, influencia especial de la moral religiosa, así como de numerosos institutos y conceptos jurídicos que son actualmente utilizados. Deberes bastante comunes en la antigüedad grecorromana fueron los de culto a los muertos y de mantener vivo el fuego sagrado de la familia. No se pueden olvidar tampoco aquellos deberes presentes en los mandamientos del Antiguo Testamento $^{7}$. Es posible también constatar la influencia ética sobre el concepto de deberes, tal como se puede observar en la obra de Marco Tulio Cícero, De officiis, que habla sobre los deberes, y que constituye una de las autoridades más nítidas a la hora de la recepción jurídica contemporánea del concepto de deber ${ }^{8}$. Asimismo, en el campo ético-moral es posible hacer referencia al muy citado deber de no hacer a los demás lo que no se desea que le hagan a uno, que es visto por los teóricos clásicos del contrato social como una ley natural, y en la perspectiva de Kant un modo de imperativo categórico.

Los anteriores son apenas algunos de los ejemplos que muestran a los deberes fundamentales. Deberes como respetar al prójimo, no perjudicar a los demás, resarcir los daños causados, no atentar contra la vida humana, mantener la palabra dada, no codiciar, cumplir con los compromisos, no apoderarse de lo ajeno, respetar la propiedad, obedecer al derecho positivo, responsabilizarse de las decisiones propias, y tantos otros que pueden ser encontrados en los más variados documentos jurídicos y no jurídicos.

En el ámbito jurídico, así como en el religioso, el incumplimiento de un deber se hacía acompañar de la correspondiente sanción. O sea, la previsión jurídica de un deber y su no cumplimiento por las personas era suficiente para que se les aplicase algún tipo de castigo (sanción). Y, de hecho, en cierto momento histórico se produce una equiparación entre lo antijurídico y el pecado. Vínculo que con el pasar de los tiempos se fue tornando más frágil en muchas sociedades hasta desaparecer cuando se produce la separación entre Estado (derecho) y religión. Es muy interesante observar que muchos de los deberes que se encuentran en los órdenes constitucionales, especialmente en el brasileño, tienen su origen en el pecado de la moral religiosa. Así, por ejemplo, desde el punto de vista de la moral religiosa apoderarse de lo ajeno constituye un pecado de los que da lugar la no observancia de uno de los diez mandamientos, cuyo resarcimiento se produce a través de una penitencia que el sujeto infractor debe cumplir, pero al mismo tiempo también es un acto delictivo que puede ser penado con una sanción privativa de libertad o restrictiva de derechos o asimismo pecuniaria.

Ahora bien, la positivación de este tipo de conducta no se refiere de forma expresa a la existencia de deberes fundamentales. Y, en verdad, la norma penal que prevé la aplicación de una determinada sanción a la comisión del delito de robo no establece literalmente el deber de no robar, sin embargo, de una lectura constitucional y jurídicamente correcta sí cabe deducir el deber general de respetar el orden jurídico y el deber de no violentar

${ }^{6}$ Peces-Barba Martínez, G., “Los deberes fundamentales”, en Doxa, Alicante, n. 4, 1987, p. 329.

7 Alcântara, M.A.C., “A face oculta dos direitos humanos: os deveres fundamentais", en Anais do XIV Congresso Nacional do CONPEDI, Fortaleza, 2006, p. 3. Disponível em: <http://conpedi.org>, Acesso em: 09 set. 2009.

${ }^{8}$ Peces-Barba Martínez, G., “Los deberes fundamentales”, en Doxa, Alicante, n. 4, 1987, p. 329. 
la situación jurídica de los demás. Así, pues, no robar es un mandamiento, una norma religiosa, que si no es respetada puede dar lugar a una sanción moral, de modo que el deber contenido en esa regla es el de respetar los mandamientos religiosos y, aún, el de no hacer a los demás lo que no se quiere para sí mismo. Del mismo modo, el llamado deber de culto y de dar alimento a los muertos y el de mantener vivo el fuego sagrado no son sino mandamientos cuya violación da lugar a una pena moral, siendo parte propiamente del deber de respetar los costumbres sociales.

\section{LOS DEBERES EN LA CONSTITUCión BRASILEÑa}

De estas notas introductorias sobre la relación entre derecho y moral cabe deducir, en principio, dos deberes fundamentales: respetar el orden jurídico-constitucional y respetar la situación jurídica de los demás. Estos son deberes universales y quizás naturales de las personas. Hay que observar que los deberes no se oponen ni sirven para restringir o limitar el alcance de los derechos fundamentales, ya que esta cuestión viene establecida en los propios derechos, o mejor dicho, en las propias normas que establecen derechos y que contienen cláusulas limitadoras de la estructura de aquéllos. Por ejemplo: las normas que aseguran la libertad de expresión y vedan el anonimato no contienen un derecho y un deber sino una limitación inherente al derecho garantizado.

La existencia de un derecho no siempre se corresponde con la existencia de un correlativo deber, lo que exceptúa la idea general de que el derecho de uno necesariamente incluye el deber de reconocimiento y respeto por parte de los demás. Aunque esa pretendida excepción no permite que se hable de deber, y sí del derecho a ser reconocido y respetado en el derecho propio. Se trataría entonces de un falso deber, porque, en verdad, la correlación entre derecho y deber no es de reciprocidad, o sea, el derecho de uno no siempre está acompañado de un correlativo deber para otro. Lo que sucede es que tanto el derecho como el deber pertenecen a la misma persona, son detentados por el mismo individuo. Así es interesante notar, como lo hizo José Casalta Nabais, que si los derechos fundamentales expresan el aspecto activo de los individuos ante el Estado y la sociedad, los deberes expresan el aspecto pasivo de la misma relación, de ahí la coexistencia entre derechos y deberes ${ }^{9}$. Esto es, siendo observada la misma relación jurídica, los derechos representan lo que el Estado debe proporcionar a los individuos, y los deberes lo que los individuos deben proporcionar al Estado. Se trata de un ciclo en el que algunas de las prestaciones estatales dependen al menos en parte del cumplimiento de deberes por parte de los individuos, pues hay derechos que dependen de la realización correcta y efectiva de deberes.

${ }^{9}$ Nabais, José Casalta, O dever fundamental de pagar impostos: contributo para a compreensão constitucional do estado fiscal contemporâneo, Coimbra, Almedina, 2004, p. 65. 
Así, los deberes fundamentales pueden ser autónomos (o genéricos) y correlativos (o conexos) a los derechos (o, aún, deberes específicos), siendo la diferencia entre unos y otros el que unos no están -aunque otros sí- relacionados material y directamente con la realización de los derechos fundamentales ${ }^{10}$. Los deberes específicos pueden relacionarse a derechos de variadas dimensiones. Así los deberes de no usar un derecho con el fin de perjudicar la situación jurídica de los demás (deber de no abusar de derechos), de promover situaciones que faciliten o que proporcionen igualdad entre los sujetos, y de respetar el compromiso de manutención de un ambiente equilibrado y sano para el desarrollo de los derechos más elementales. Los deberes autónomos independen de una relación con derechos, pudiéndose citar los deberes de inscripción de votantes y de militares, y el deber de votación. Hay también deberes híbridos, como el deber de pagar tributos, cuya utilidad también tiene que ver con la realización de los derechos, pues es nítido el objetivo de las exacciones de financiar la manutención de la maquinaria estatal, situación en la que es claro su papel remunerador. Es también el caso del deber de atender a la función social de la propiedad, que para algunos juristas no es un deber, sino una limitación inherente al propio derecho de propiedad ${ }^{11}$, lo que todavía no se adopta acá, por entender que es deber del propietario cumplir con la función social de su propiedad para poder disfrutar del derecho que le es correlativo.

Tales deberes pueden ser expresos o implícitos, se pueden o no ser directamente identificados en los enunciados normativos constitucionales. Aunque no exista formulación expresa, por ejemplo, de que pagar tributos es un deber, o sea, aunque no exista en el texto constitucional el enunciado que explicite como deber tal contribución pecuniaria, desde los enunciados de derecho financiero en la CR es clara la referencia al deber de pagar tributos, bien como, por ejemplo, en el artículo 14, párrafo primero, de la CR, en que es clara la obligatoriedad de inscripción de votantes para los brasileños alfabetizados mayores de 18 y menores de 70 años. No entenderlo así vendría a significar el absurdo de que el texto fundamental brasileño no contiene ninguna referencia de la que poder extraer los deberes de respeto a la situación jurídica de terceros y de respeto al mismo orden jurídico brasileño ${ }^{12}$. Esos deberes son formulaciones tanto doctrinarias cuanto jurisprudenciales pacíficas aun cuando no poseen ningún rastro de existencia en el texto magno.

${ }^{10}$ Sarlet, I. W., A eficácia dos direitos fundamentais: uma teoria geral dos direitos fundamentais na perspectiva constitucional, 10. ed., Porto Alegre, Livraria do Advogado, 2009, p. 228.

${ }^{11}$ Dimoulis, D. y Martins, L., Teoria geral dos direitos fundamentais, São Paulo, Revista dos Tribunais, 2007 , p. 78.

${ }^{12}$ Normas constitucionales que establecen las organizaciones del Estado y de los Poderes no son normas que instituyen propiamente deberes, pero son normas de competencia y organización que tienen que ser respetadas debido al propio sistema constitucional. O sea, existe el deber de respetar las normas constitucionales y legales que establecen criterios de competencia y de organización para el Estados y los Poderes estatales. Además, lo mismo se podría decir de deberes genéricos de legislar, juzgar y administrar/ejecutar que no son propiamente deberes, sino normas de competencia que deben ser respetadas. 
Peces-Barba Martínez ${ }^{13}$ y Rubio Llorente ${ }^{14}$ hacen referencia a los deberes positivos (o prestacionales) y deberes negativos (o defensivos), que consisten respectivamente en un hacer o en un no-hacer o soportar ciertas conductas ${ }^{15}$. Tanto el deber de no interferir en la situación jurídica de terceros cuanto el deber de preservar el medio ambiente son deberes negativos, mientras que deberes como el de pagar tributos y el de inscripción de votantes y militares son positivos. También se hace referencia a los deberes constitucionales y deberes fundamentales, el primer tipo englobando el segundo, de manera que los deberes fundamentales son también constitucionales, siendo la diferencia la que los deberes fundamentales sólo pueden tener previsión constitucional, mientras que los deberes constitucionales pueden tener previsión en normas constitucionales e infraconstitucionales.

Todos esos aspectos no dejan de ser más que preliminares a cualquier tentativa de proponer una teoría general de los deberes fundamentales. En todo caso, la línea adoptada -eso es, simplemente proponer una introducción a la temática- viene a constatar la necesidad de hablar en el régimen jurídico-constitucional brasileño de los deberes fundamentales. Como ya he mencionado, la CR en su capítulo I del título II ha hecho referencia a la existencia de deberes fundamentales.

A pesar del necesario análisis del texto constitucional con el fin de extraer deberes, se hace muy dificultosa la formación de una lista de los mismos, ya que hay deberes implícitos respecto de los que apenas existe consenso sobre su existencia, sino más bien disenso sobre ellos ${ }^{16}$. Hay también muchos deberes que son semejantes a las posibles limitaciones contenidas en los propios derechos (teoría interna) o restricciones a los derechos (teoría externa), sea por simple similitud o sea por cuestión de su empleo como justificación de tales limitaciones o restricciones ${ }^{17}$; así el deber de respetar la función social de la propiedad es solo una restricción al derecho de propiedad, pero no un deber propiamente dicho, el deber de votación, a su vez, restringe efectivamente la libertad del individuo, siendo un deber - de una manera bien general, los deberes específicos tienden a comportarse como restricciones y a veces a ser restricciones comportándose como deberes, en cuanto los deberes autónomos (y también los híbridos), a pesar de restringir los derechos, son efectivamente deberes.

Si no hay una dogmática que determine cuáles son efectivamente los deberes y cuáles son las restricciones a los derechos, es posible afirmar, entonces, que, desde un análisis estricto de la $\mathrm{CR}$, no se puede decir con precisión que hay un número determinado de

13 Peces-Barba Martínez, G., “Los deberes fundamentales”, en Doxa, Alicante, n. 4, 1987, p. 336.

14 Rubio Llorente, F., "Los deberes constitucionales”, en Revista Española de Derecho Constitucional, Madrid, n. 62, 2001, p. 21 y ss.

${ }^{15}$ Ver, también: Garzón Valdés, E., "Los deberes positivos generales y su fundamentación”, en Doxa, Alicante, n. 3, 1986, p. 17-33; Laporta, F. J., "Algunos problemas de los deberes positivos generales (observaciones a un artículo de Ernesto Garzón Valdés)”, en Doxa, Alicante, n. 3, 1986, p. 55-63.

${ }^{16}$ Sarlet, I.W., A eficácia dos direitos fundamentais: uma teoria geral dos direitos fundamentais na perspectiva constitucional, 10. ed., Porto Alegre, Livraria do Advogado, 2009, p. 229.

${ }^{17}$ Canotilho, J.J.G. y Moreira, V., Constituição da República portuguesa anotada, 4. ed., Coimbra, Coimbra Editora, 2007, p. 320-321. Sobre las teorías interna y externa, vease Silva, V. A. Direitos fundamentais: conteúdo essencial, restrições e eficácia, São Paulo, Malheiros, 2009, p. 131. 
deberes, ya que los enunciados de la $\mathrm{CR}$ no son claros en ese sentido, al contrario del caso de los derechos fundamentales. En vista de esa dificultad, sólo es posible enumerar una lista de deberes fundamentales presentes en el texto constitucional brasileño, por ejemplo: deber de respeto a la vida, la libertad, la igualdad, a la seguridad y a la propiedad (art. $5^{\circ}$, caput); deber de hacer o no hacer alguna cosa en virtud de ley (art. $5^{\circ}$, II); deber de no torturar o someter a otros a trato inhumano o degradante (art. $5^{\circ}$, III); deber de indemnización por daño material, moral o imagen (art. $5^{\circ}$, VI-VIII); deber de respetar la intimidad, vida privada, honor, imagen y la casa del individuo, así como su correspondencia, comunicaciones telegráficas, de datos y telefónicas (art. $5^{\circ}, \mathrm{X}-\mathrm{XII}$ ); deber de respetar la propiedad (art. $\left.5^{\circ}, \mathrm{XXII}\right)$; deber de atender a la función social de la propiedad (art. $\left.5^{\circ}, \mathrm{XXIII}\right)$; deber de ayudar al Estado y/o la sociedad en caso de inminente riesgo público (art. $5^{\circ}, \mathrm{XXV}$ ); deber de respetar las creaciones ajenas, así como su valor (art. 5 XXVII-XXIX); deberes de inscripción de votantes, de votación y de filiación partidaria para elegirse (art. 14); deber de inscripción de militares (art. 143); deber de pagar tributos (arts. 145-162); deber de contribuir para la seguridad social (arts. $194 \mathrm{y}$ 195); deber de educar (art. 205); deber de promover y proteger el patrimonio cultural (arts. 215 y 216); deber de preservar el medio ambiente (art. 225); deberes conyugales (art. 226, $\$ 5^{\circ}$ ); deber de atender a los niños y al adolescente (art. 227); deber de amparar a los ancianos (art. 230).

De lo anterior se deduce que, a pesar del extenso - pero no exhaustivo- rol que ocupan los deberes, sin embargo existe una gran dificultad para hacer una lista cerrada de deberes fundamentales si tenemos en cuenta únicamente el texto constitucional. Este hecho se pone de manifiesto cuando los juristas al clasificar ciertas normas constitucionales dicen de ellas que establecen una restricción a los derechos pero no a los deberes. Esta es una observación muy interesante, y quizás la que tiene más relación al escaso tratamiento dado a los deberes en la dogmática jurídica, cuestión que los teóricos del derecho constitucional tendrán que enfrentar para que se forme una teoría de los deberes fundamentales.

Además de la cuestión de la conformación de una lista de deberes, en relación al régimen jurídico-constitucional brasileño de deberes fundamentales, no hay que dejar de observar el art. $5^{\circ}, \S 1^{\circ}$, de la CR, que establece que las normas de derechos y garantías fundamentales, así como las de deberes fundamentales, en una interpretación extensiva, tienen aplicabilidad inmediata. Es decir, los deberes están sujetos a esa norma según se desprende de la simple lectura de la Constitución. Bien, si el $\S 1^{\circ}$ habla de "derechos y garantías fundamentales”, ello se refiere, así, pero no sólo, a normas contenidas en el título II de la CR, que, a su vez, contiene, ya en su capítulo I, la previsión de derechos y deberes individuales y colectivos. Si en el peculiar caso de los derechos fundamentales la cuestión de la aplicabilidad inmediata genere algunas polémicas, ¿qué se podrá decir en cuanto a los deberes fundamentales, especialmente por ser una cuestión todavía nueva en la doctrina? ${ }^{18}$.

${ }^{18}$ Sarlet, I.W., A eficácia dos direitos fundamentais: uma teoria geral dos direitos fundamentais na perspectiva constitucional, 10. ed., Porto Alegre, Livraria do Advogado, 2009, p. 230. 


\section{Concepto de Deberes fundamentales}

La introducción a los deberes fundamentales en el sistema constitucional tiene que ser completada con la pretensión de abordar su conceptuación. Peces-Barba formula, con base a sus ponderaciones, un concepto en el que trabaja con las siguientes ideas ${ }^{19}$ : "dimensiones básicas de la vida del hombre en sociedad"; "bienes de primordial importancia"; "satisfacción de necesidades básicas o que afectan a sectores especialmente importantes para la organización y el funcionamiento de las instituciones públicas"; "ejercicio de derechos fundamentales”. En verdad, tales ideas parecen tener relación con la mayoría de los deberes fundamentales contenidos en la CR. Pero es posible ampliar el rol de ideas que en principio forman parte de un concepto de deberes, con otras ideas presentadas por André Ramos Tavares ${ }^{20}$ : "prohibición del uso de derechos para practicar ilícitos"; "prohibición del uso de derechos para justificar la irresponsabilidad civil"; "prohibición del uso de derechos para anular otros derechos constitucionales"; "prohibición al uso de derechos para anular los mismos derechos de otras personas”. Pues bien, todas esas ideas permiten que se conforme un concepto adecuado y plausible de deberes fundamentales. De este modo, nuestro concepto afirma: deberes que cada individuo tiene con el Estado y con la sociedad de (a) proporcionar la formación de una base material que satisfaga las necesidades básicas de las instituciones públicas y realice los bienes de primordial importancia, para que exista el correcto ejercicio de los derechos fundamentales ${ }^{21}$ y de (b) respetar la situación jurídica de terceros y las normas constitucionales y legales.

En cuanto a la posibilidad de que los deberes actuaren como limitadores del ejercicio de derechos, además de los deberes expresos como el de función social de la propiedad y el de votación, pueden citarse aquí los que se entienden como deberes implícitos -el de respeto a la situación jurídica de terceros y el de respeto a las normas legales y constitucionales vigentes. Ahora bien, a pesar de ejercer tal limitación, no hay que confundir las normas que establecen deberes y las que restringen derechos. Al contrario, ese tipo de deberes limitadores son tratados como cláusulas limitativas del ejercicio de derechos, específicamente de las libertades de los individuos. Así, por ejemplo, el caso de la función social que limita la propiedad, el deber de votación y el deber de respeto a la situación jurídica de terceros que limita el abuso de derechos.

Así, considerando el esbozo conceptual hecho, los deberes implícitos son parte de la parte (b), en cuanto los deberes expresos están en la parte (a). La primera parte confirma los derechos prioritarios a toda y cualquier persona para suplir necesidades básicas de todos. Es importante que las dos clases de deberes sean bien explicadas, para que se llegue a un concepto al menos provisorio de que sean deberes fundamentales. En breve síntesis, una de las clases funciona como garantía de derechos, en cuanto la otra actúa como garantía del orden constitucional. Lo que se puede objetar es que los

19 Peces-Barba Martínez, G., “Los deberes fundamentales”, en Doxa, Alicante, n. 4, 1987, p. 336.

20 Tavares, A.R., Curso de direito constitucional, 6. ed., São Paulo, Saraiva, 2008, p. 488.

${ }^{21}$ Esto parece ser también el entendimiento de Garzón Valdés, E., "Los deberes positivos generales y su fundamentación”, en Doxa, Alicante, n. 3, 1986, p. 17. 
deberes implícitos (garantías del orden constitucional) envuelven la clase de deberes explícitos, que -hay que decir- se encuentran previstos en el ordenamiento jurídicoconstitucional, y por las humildes pretensiones de esto trabajo, su tratamiento debe ser delegado para otra oportunidad.

\section{ConClusión}

Vistas algunas notas introductorias en el tema de los deberes fundamentales, es posible concluir con el propósito, preliminar e incipiente, de proporcionar un concepto en relación al cual se deba hacer una reflexión: deberes fundamentales son los que, autónoma o conexamente con los derechos, tienen los individuos con el Estado y con la sociedad de proporcionar medios para la manutención de las instituciones públicas y para la satisfacción de las necesidades humanas básicas y de respetar la situación jurídica de terceros y las normas del sistema constitucional, para que tenga lugar un correcto ejercicio de los derechos fundamentales.

\section{BiBLiografía}

AlcÂntara, M.A.C., "A face oculta dos direitos humanos: os deveres fundamentais", Anais do XIV Congresso Nacional do CONPEDI, Fortaleza, 2006. Disponível em: <http://conpedi. org >, Acesso em: 09 set. 2009.

CAnotilho, J.J.G., "Das constituições dos direitos à crítica dos direitos", Direito Público, Brasília, n. 7, 2005.

Canotilho, J.J.G. y Moreira, V., Constituição da República portuguesa anotada, 4. ed., Coimbra, Coimbra Editora, 2007.

Dimoulis, D. y Martins, L., Teoria geral dos direitos fundamentais, São Paulo, Revista dos Tribunais, 2007.

Garzón Valdés, E., "Los deberes positivos generales y su fundamentación”, Doxa, Alicante, n. 3, 1986.

LAPORTA, F.J., "Algunos problemas de los deberes positivos generales (observaciones a un artículo de Ernesto Garzón Valdés)”, Doxa, Alicante, n. 3, 1986.

Lopes, A.M.D., "A participação política das minorias no Estado democrático de direito brasileiro”, en: Lima, M. M.; Albuquerque, P. A. de M. (org.), Democracia, direito e política: estudos internacionais em homenagem a Friedrich Müller, Florianópolis: Conceito, 2006.

NabAIs, J. C., O dever fundamental de pagar impostos: contributo para a compreensão constitucional do estado fiscal contemporâneo, Coimbra, Almedina, 2004.

Peces-Barba Martínez, G., "Los deberes fundamentales", Doxa, Alicante, n. 4, 1987.

Rubio Llorente, F., "Los deberes constitucionales", Revista Española de Derecho Constitucional, Madrid, n. 62, 2001.

SARLET, I.W., A eficácia dos direitos fundamentais: uma teoria geral dos direitos fundamentais na perspectiva constitucional, 10. ed., Porto Alegre, Livraria do Advogado, 2009.

Silva, V.A., Direitos fundamentais: conteúdo essencial, restrições e eficácia, São Paulo, Malheiros, 2009.

Tavares, A. R., Custo de direito constitucional, 6. ed., São Paulo, Saraiva, 2008. 